\title{
PENGENDALIAN SUHU RUANGAN MENGGUNAKAN MENGGUNAKAN FAN DAN DHT11 BERBASIS ARDUINO
}

\author{
Rachmat Aulia', Rahmat Aulia Fauzan², Imran Lubis ${ }^{3}$ \\ ${ }^{1,2,3}$ Program Studi Teknik Informatika Universitas Harapan Medan \\ Jl. H.M. Jhoni No.70 Medan \\ Ijackm4t@gmail.com, 2cool.ozans1604@gmail.com, 3imran.loebis.medan@gmail.com
}

\begin{abstract}
Abstrak-Pada zaman sekarang pohon - pohon dikota sedikit disebabkan banyaknya pertumbuhan pembangunan yang cukup pesat mengakibatkan suhu udara semakin panas dan berdampak bagi manusia. Masalah dalam kehidupan sehari-hari yang umumnya dialami para pekerja adalah suhu di ruangan kerja cenderung panas, kelembaban udara tinggi, dan sedikitnya ventilasi yang tersedia. Selain itu lingkungan kerja fisik berpengaruh bagi para pekerja dalam menjalankan tugas-tugas yang diembannya. Peningkatan suhu dalam suatu ruangan kerja dapat menurunkan semangat kerja sehingga kinerja yang dihasilkan tidak maksimal. Agar para pekerja tersebut dapat bekerja secara efisien, maka dirancanglah sebuah perangkat pengendali suhu ruangan secara otomatis dengan harga yang ekonomi suntuk menghasilkan suhu ruangan yang sejuk dan nyaman. Perangkat yang dirancang ini menggunakan lebih dari satu fan (kipas) sebagai motorik, menggunakan sensor DHT11 sebagai pendeteksi suhu dalam suatu ruangan, dan menghasilkan output tinggi/rendahnya suhu yang ditampilkan secara real-time menggunakan LCD (Liquid Crystal Display) berukuran 16 × 2 .
\end{abstract}

Kata Kunci-Arduino uno R3, Bluetooth HC-05, Dht 11, Fan Dc, Relay 4 Chanel, Pendingin Suhu Ruangan otomatis.

Abstract-In this day and age the trees in the city are few due to the large number of development growths which are quite rapid resulting in the air temperature being hotter and impacting humans. Problems in daily life that generally experienced by workers are the temperature in the work space tends to be hot, high humidity, and the lack of available ventilation. In addition, the physical work environment affects workers in carrying out their duties. Increasing the temperature in a work space can reduce morale so that the resulting performance is not optimal. So that these workers can work efficiently, an automatic room temperature control device is designed at an economical price to produce a cool and comfortable room temperature. This designed device uses more than one fan as a motor, uses the DHT 11 sensor as a temperature detector in a room, and produces a high / low temperature output that is displayed in real-time using a $16 \times 2$ LCD (Liquid Crystal Display).

Key Word-Arduino Uno R3, Bluetooth HC-05, Dht 11 Fan, Relay 4 Chanel, Coolant Temperature room auto.

\section{PENDAHULUAN}

Pada keseharian dalam beraktivitas seseorang membutuhkan tempat atau ruangan yang nyaman agar dapat berkonsentrasi pada suatu bidang yang dikerjakannya. Tempat lingkungan dapat mempengaruhi salah satu faktor kenyamanan dalam ruangan untuk beraktivitas.

Suhu dan kelembaban udara pada ruangan dapat mempengaruhi efektivitas kegiatan dalam bekerja. Bekerja pada suhu ruangan yang cukup panas pastinya kemampuan fisik tubuh menurun yang menyebabkan keletihan dan apabila suhu pada ruangan yang cukup dingin mengakibatkan hilangnya fleksibilitas motorik pada tubuh menyebabkan timbulnya kekakuan terhadap fisik tubuh.

Penelitian terdahulu yang telah dilakukan berkenaan dengan judul yang diangkat pernah dibahas oleh Hannif Izzatul Islam dkk pada tahun 2016 dengan judul " Sistem Kendali Suhu Dan Pemantauan Kelembaban Udara pada Ruangan Berbasis Arduino uno dengan menggunakan Sensor DHT22 dan Passive Infrared (PIR)". Membahas tentang membuat alat miniatur yang berfungsi mengontrol suhu serta memantau kelembaban udara menggunakan sensor DHT22 sebagai sumber inputannya, dalam pengujian 
ini pada sensor DHT22 lebih peka terhadap Relative Humidity (RH), dikarenakan ketika diberikan udara panas tersebut kelembaban yang terukur lebih cepat

Page|31 mengalami penyesuaian dan berbeda dengan termometer digital AZ-HT-02 yang lambat untuk menyesuaikan kelembaban udara pada ruangan [1].

Dengan adanya penelitian terdahulu maka terciptalah suatu gagasan ide membuat pengendalian suhu ruangan menggunakan menggunakan fan dan dht11 berbasis arduino. Tujuan dari perancangan alat ini adalah untuk mewujudkan sebuah perangkat pengendali suhu ruangan dengan cara mengontrol suhu sebuah ruangan, apabila suhu ruangan tersebut terasa panas yang berlebihan maka secara otomatis nantinya dapat di atur menjadi lebih normal dengan menggunakan fan dc sebagai motorik utama untuk menormalkan suhu yang dilengkapi alat pengontrol pembaca suhu dengan dht11 sebagai pendeteksi suhu terhadap ruangan yang secara realtime dan akan ditampilkan tinggi/rendahnya suhu pada sebuah lcd sebagai tampilan monitoring suhu nya. Dimana setiap masing - masing fan dc akan bergerak sesuai yang diperlukan dengan batasan ketentuan suhu yang telah ditentukan.

\section{TINJAUAN PUSTAKA}

\section{A. Arduino}

Arduino adalah sebuah platform komputasi fisik open source berbasiskan Rangkaian input/output sederhana (I/O) dan lingkungan pengembangan yang mengimplementasikan bahasa Processing [2].

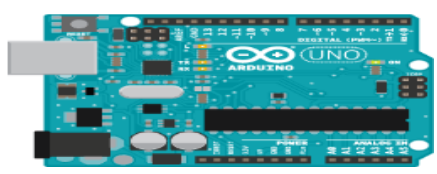

Gbr. 1 Arduino uno

Sumber: www.arduino.cc

\section{B. Fan DC $12 \mathrm{~V}$}

Fan adalah mengatur volume panas udara agar ruangan yang tidak mengalami suhu panas dan dapat bersirkulasi udara secara normal. Pada umumnya kipas angin dimanfaatkan untuk pendingin udara, penyegar udara, ventilasi (exhaust fan), atau pengering (umumnya memakai komponen penghasil panas). Terdapat dua jenis kipas angin berdasarkan arah angin yang dihasilkan, yaitu kipas angin centrifugal (angin mengalir searah dengan poros kipas) dan kipas angin axial (angin mengalir secara paralel dengan poros kipas) [3].

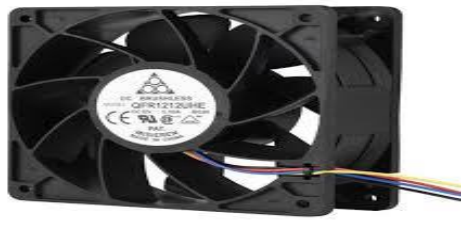

Gbr. 2 Fan DC

Sumber : www..trigunadharma.ac.id

\section{DHT 11}

Sensor suhu dan kelembaban dht11, Sensor yang digunakan untuk mendeteksi suhu sekaligus mengukur perubahan kelembapan dalam suatu tempat adalah sensor dht11[4]

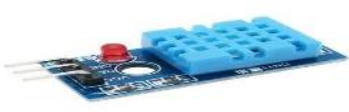

Gbr.3 Sensor DHT 11

Sumber : https://www.indonesian.alibaba.com

\section{D. $I 2 C L C D$}

Liquid Crystal Display (LCD) adalah sebuah peralatan elektronik yang berfungsi untuk menampilkan output sebuah sistem dengan cara membentuk suatu citra atau gambaran pada sebuah layar. Secara garis besar komponen penyusun lcd terdiri dari kristal cair (liquid crystal) yang diapit oleh 2 buah elektroda transparan dan 2 buah filter polarisasi (polarizing filter) [5].

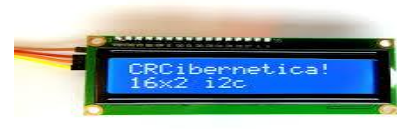

Gbr. 4 LCD 16x2

Sumber : https://www.bigcmmerce.com

\section{E. Relay $4 \mathrm{CH}$}

Relay itu adalah saklar untuk menghidupkan atau mematikan sebuah perangkat elektronika dengan memanfaatkan masukan dari output sebuah komponen elektronika lainnya. Relay arduino mempunyai 3 buah input yang masing masing berfungsi sebagai kontrol untuk menghidupkan relay. Pin tersebut adalah pin GND, VCC, dan IN. GND untuk ground atau tegangan 0 volt (-), VCC Untuk tegangan positif $+5 \mathrm{v}$, Sedangkan $I N$ untuk masukan dari sensor yang lainnya yang berfungsi untuk menggerakkan sebuah sensor relay [6]. 
Page | 32

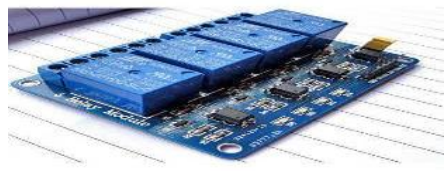

Gbr. 5 Relay $4 \mathrm{CH}$

Sumber: https://www. yourduino.com

\section{F. $\quad I 2 C L C D$}

Inter Integrated Circuit atau sering disebut $\mathrm{I} 2 \mathrm{C}$ adalah standar komunikasi serial dua arah menggunakan dua saluran yang didisain khusus untuk mengirim maupun menerima data. Sistem I2C terdiri dari saluran SCL (Serial Clock) dan SDA (Serial Data) yang membawa informasi data antara I2C dengan pengontrolnya. Piranti yang dihubungkan dengan sistem I2C Bus dapat dioperasikan sebagai master dan slave. Master adalah piranti yang memulai transfer data pada I2C Bus dengan membentuk sinyal start, mengakhiri transfer data dengan membentuk sinyal stop, dan membangkitkan sinyal clock. Slave adalah piranti yang dialamati master

I2C LCD mempunyai 16 pin output yang bisa dihubungkan dengan pin lcd secara langsung (disolder permanen) dan memiliki 4 pin input (VCC, GND, SDA, SCL). Untuk menghemat penggunaan pin pada LCD digunakan I2C, apabila tidak menggunakan I2C maka harus menggunakan 5 pin digital [7].

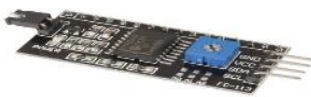

Gbr. 6 I2C LCD

Sumber : https://www.deepbluembedded.com

\section{G. Adaptor $12 \mathrm{~V}$}

Power supply atau catu daya adalah salah satu hardware di dalam perangkat computer yang berperan untuk memberikan suplai daya. Biasanya komponen power supplay ini bisa ditemukan pada chasing komputer dan berbentuk persegi. Pada dasarnya power supply membutuhkan sumber listrik yang kemudian diubah menjadi energi yang menggerakkan perangkat elektronik. Sistem kerjanya cukup sederhana yakni dengan mengubah daya $120 \mathrm{~V}$ ke dalam bentuk aliran dengan daya yang sesuai kebutuhan komponen komponen tersebut. Sesuai dengan pengertian power supply pada komputer, maka fungsi utamanya adalah untuk mengubah arus AC menjadi arus DC yang kemudian diubah menjadi daya atau energi yang dibutuhkan komponen - komponen pada komputer seperti motherboard, CD Room, hardisk, dan komponen lainnya. Berdasarkan rancangannya, power supply dapat diklasifikasikan menjadi dua jenis, yaitu:

a. Power supply/ catu daya internal.

b. Yaitu power supply yang dibuat terintegrasi dengan motherboard atau papan rangkaian induk. Contohnya; amplifier, televisi, dvd Player, power supply-nya menyatu dengan motherboard di dalam chasing perangkat tersebut.

c. Power Supply/ catu daya eksternal yaitu power supply yang dibuat terpisah dari motherboard perangkat elektroniknya. Contohnya charger laptop dan charger smartphone [8].

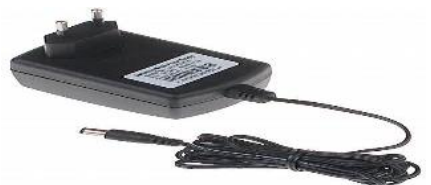

Gbr. 7 Adaptor $12 \mathrm{~V}$

Sumber : https://www.microsat.com.

\section{H. Bluetooth $\mathrm{HC}-05$}

Bluetooth adalah sebuah teknologi komunikasi wireless (tanpa kabel) yang beroperasi dalam pita frekuensi 2,4 GHz unlicensed ISM (Industrial, Scientific and Medical) dengan menggunakan sebuah frequency hopping tranceiver yang mampu menyediakan layanan komunikasi data dan suara secara realtime antara host-host bluetooth dengan jarak jangkauan layanan yang terbatas sekitar 10 meter [9]

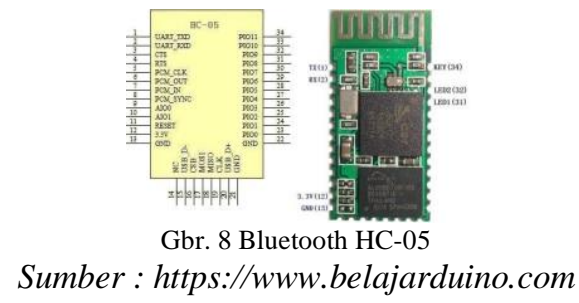

\section{Flow Chart Sistem}

Flowchart merupakan diagram dengan simbol simbol yang digunakan untuk menjelaskan proses atau langkah - langkah dalam penelitian. Beberapa proses tersebut digabungkan dengan menggunakan tanda panah sesuai urutannya. Diagram ini juga berfungsi untuk menyelesaikan masalah yang ada dalam proses - proses penelitian. Berikut di bawah ini pada gambar 9 merupakan flowchart sistem keseluruhan komponen perancangan alat pengendalian suhu ruangan menggunakan fan dan dht 11 yang akan direalisasikan. 


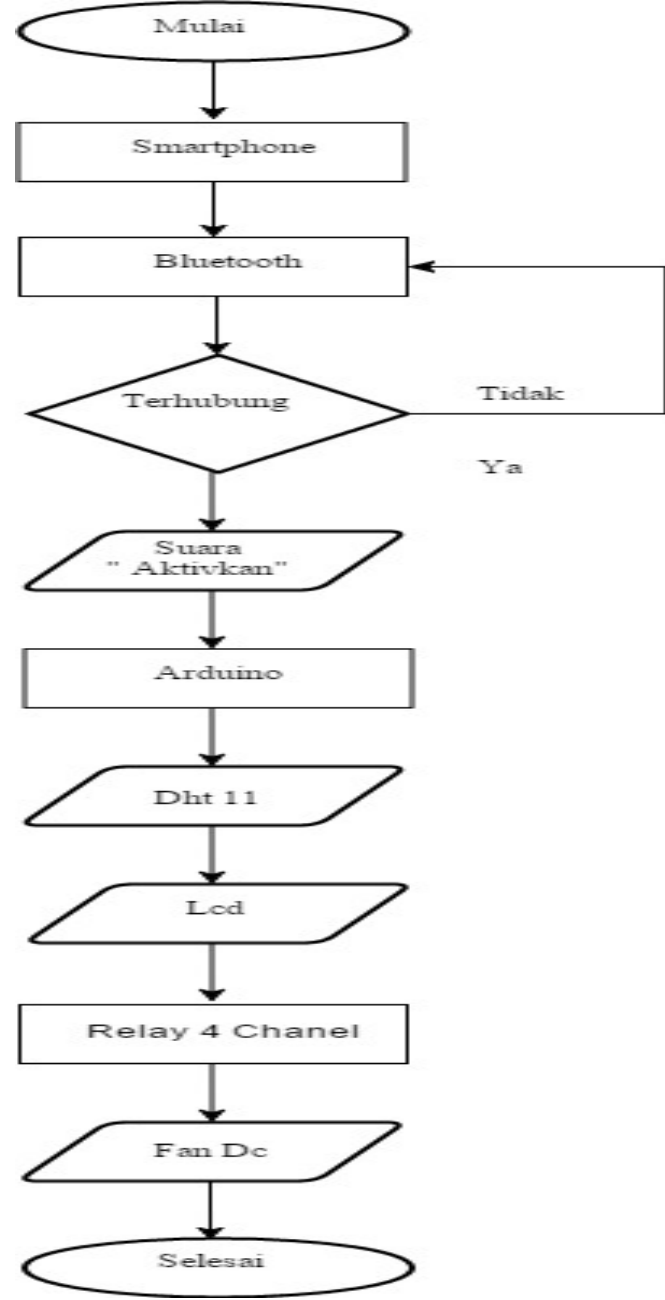

Gbr. 9 Flowchart sistem keseluruhan komponen

Keterangan gambar flowchart sistem:

1. Akan dimana saat memulai kita harus mengaktifkan bluetooth pada smartphone.

2. Lalu koneksikan ip bluetooth hc - 05 yang terhubung dengan arduino

3. Jika tidak terhubung maka periksa kembali dimana kesalahan prosesnya

4. Jika terhubung maka perintah selanjutnya untuk mengucapkan kata aktifkan pada voice di smartphone menggunakan suara.

5. Jika kata yang diucapkan berbeda maka sistem tidak akan memulainya.

6. Setelah suara yang telah diucapkan maka arduino memproses perintah tersebut, arduino dapat memproses dikarenakan telah diberi coding program untuk membaca proses tersebut agar berjalan dengan sesuai coding yang ditanamkan pada arduino.

7. Setelah arduino memproses makan dht 11 memulai untuk menginput nilai suhu disekitar nya.

8. Lalu dht 11 menampilkan suhu melalui dari lcd dan dht 11 juga melakukan perintah secara bersamaan kepada arduino untuk diproses data suhu.

9. Lalu akan dilanjut ke relay 4 ch dimana relay ini berfungsi menghidupkan dan mematikan fan.

10. Setelah relay $4 \mathrm{ch}$ telah menerima perintah dari dht11 maka relay tersebut memproses perintah tersebut dan melakukan tindakan sesuai keputusan untuk mengaktifkan dan mematikan fan dc.

\section{J. Perancangan Hardware.}

Berikut ini adalah perancangan hardware dari keras perancangan alat pengendalian suhu ruangan menggunakan fan dan dht 11 terdiri dari beberapa komponen yang diperlukan yaitu, Arduino uno R3, Bluetooth HC- 05, Dht 11, Lcd, Relay, Fan Dc.

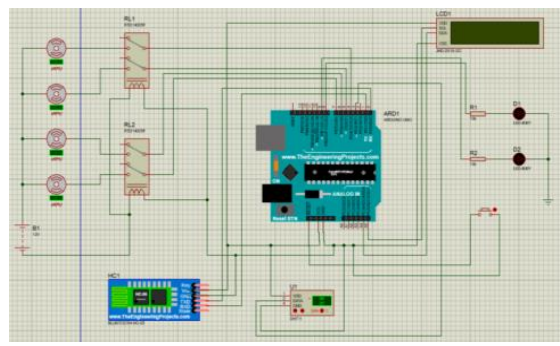

Gbr. 10 Perancangan keseluruhan hardware

Pada gambar perancangan hardware di atas, masing masing komponen terhubung dengan Arduino melalui pin yang berbeda. Berikut adalah penjelasan hubungan dari setiap komponen ke Arduino :

1. Bluetooth HC-05 ke Arduino

a. Pin VCC (HC-05) terhubung ke pin 5V (Arduino).

b. Pin GND (HC-05) terhubung ke pin GND (Arduino)

c. Pin RX (HC-05) terhubung ke pin 1 (Arduino).

d. Pin TX (HC-05) terhubung ke pin 0 (Arduino).

Dalam tampilan gambar 3.3 , bahwa pin $5 \mathrm{~V}$ pada arduino itu merupakan pin vec disebabkan karena ini simulasi melalui 
proteus jadi tampilan dari arduino tidak sama seperti arduino aslinya yang mendetail.

Page | 34 2. Dht 11 ke Arduino

a. Pin VCC (Dht11) terhubung ke pin 5V (Arduino).

b. Pin Data (Dht11) terhubung ke pin 3 (Arduino).

c. Pin GND (Dht11) terhubung ke pin GND (Arduino).

3. Lcd $16 \times 2$ ke Arduino

a. Pin VCC (Lcd) terhubung ke pin 5V (Arduino).

b. Pin SCL (Dht11) terhubung ke pin A5 (Arduino).

c. Pin SDA (Dht11) terhubung ke pin A4 (Arduino).

d. Pin VSS (Dht11) terhubung ke pin GND (Arduino).

4. Relay 4 ch ke Arduino

a. IN 1 (Relay) terhubung ke pin 4 (Arduino).

b. IN 2 (Relay) terhubung ke pin 5 (Arduino).

c. IN 3 (Relay) terhubung ke pin 6 (Arduino).

d. IN 4 (Relay) terhubung ke pin 7 (Arduino).

5. Button ke arduino

a. kaki 1 (Button) terhubung ke Pin Reset (Arduino).

b. kaki 2 (Button) terhubung ke GND (Arduino).

\section{K. Hasil Perancangan Komponen}

Pada bagian ini akan digambar miniatur untuk menunjukkan posisi letak perangkat yang telah terpasang. Gambar ini di buat menggunakan aplikasi sketch up. Gambar ini berfungsi sebagai tampilan visual dari perangkat tersebut.

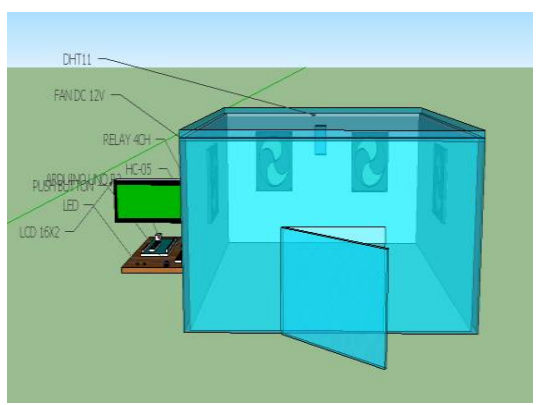

Gbr.11 Desain Tampilan Alat Setelah Perangkat Terpasang

Pada gambar ini tampak komponen - komponen yang terdiri dari dht11.relay 4ch, Arduino, fan dc, led, push button dan lcd terhubung dalam sebuah ruangan.

\section{HASIL DAN PEMBAHASAN}

TABEL I

KONDISI SUHU AGAR FAN DAPAT BERPUTAR DAN

\begin{tabular}{|c|c|c|c|c|}
\hline \multirow{2}{*}{ Suhu } & \multicolumn{4}{|c|}{ Keadaan } \\
\cline { 2 - 5 } & Fan 1 & Fan 2 & Fan 3 & Fan 4 \\
\hline $0^{0} \mathrm{C}-29^{0} \mathrm{C}$ & Off & Off & Off & Off \\
\hline $30^{\circ} \mathrm{C}-32^{\circ} \mathrm{C}$ & On & Off & Off & Off \\
\hline $33^{\circ} \mathrm{C}-35^{\circ} \mathrm{C}$ & On & On & Off & Off \\
\hline $36^{0} \mathrm{C}-37^{0} \mathrm{C}$ & On & On & On & Off \\
\hline $38^{0} \mathrm{C}$ & On & On & On & On \\
\hline
\end{tabular}

Tabel diatas merupakan tabel kondisi suhu agar fan dapat berfungsi berputar atau berhenti bekerja, dimana suhu selalu berubah - ubah dan fan terus mengikuti pola ketentuan suhu dan akan berfungsi sesuai ketentuannya. Jika terjadi penurunan suhu maka fan akan tetap bekerja sesuai ketentuan yang diterapkan pada tabel II.

TABEL II

TABEL PERCOBAAN SAAT MEMASUKKAN BENDA PADA OBJEK RANCANGAN

\begin{tabular}{|c|c|c|}
\hline No & Percobaan & Keterangan \\
\hline 1. & $\begin{array}{l}\text { Kondisi alat sebelum } \\
\text { melakukan percobaan } \\
\text { yang pertama berada } \\
\text { dalam ruang tamu } \\
\text { dalam cuaca hujan } \\
\text { telah selesai dan } \\
\text { belum ada media } \\
\text { panas dari lilin yang } \\
\text { diletakkan dalam } \\
\text { miniatur ruangan. }\end{array}$ & $\begin{array}{l}\text { Dalam keadaan ini } \\
\text { yang terjadi pada } \\
\text { miniatur ruangan saat } \\
\text { di sebelum diuji } \\
\text { terdapat nilai suhu } \\
\text { temperatur sekitar } \\
\text { sebesar } 30,00^{\circ} \mathrm{C} \text {. }\end{array}$ \\
\hline 2. & $\begin{array}{l}\text { Pengujian pertama, } \\
\text { memasukkan media } \\
\text { panas dari lilin } \\
\text { sebanyak } 1 \text { lilin dalam } \\
\text { waktu } 10 \text { menit }\end{array}$ & $\begin{array}{l}\text { Dalam keadaan ini } \\
\text { yang terjadi pada } \\
\text { miniatur ruangan } \\
\text { setelah diuji coba } \\
\text { terdapat nilai suhu } \\
\text { temperatur sekitar } \\
\text { sebesar } 32,20^{\circ} \mathrm{C} \text {. }\end{array}$ \\
\hline 3. & $\begin{array}{l}\text { Pengujian kedua, } \\
\text { dengan memasukkan } \\
\text { media panas dari lilin } \\
\text { sebanyak dua lilin } \\
\text { dalam waktu } 10 \text { menit }\end{array}$ & $\begin{array}{l}\text { Dalam keadaan ini } \\
\text { yang terjadi pada } \\
\text { miniatur ruangan } \\
\text { setelah diuji coba } \\
\text { terdapat nilai suhu } \\
\text { temperatur sekitar } \\
\text { sebesar } 33,10^{\circ} \mathrm{C}\end{array}$ \\
\hline
\end{tabular}


4. Pengujian ketiga, Dalam keadaan ini dengan memasukkan yang terjadi pada media panas dari lilin miniatur ruangan sebanyak tiga lilin setelah diuji coba dalam waktu 10 menit terdapat nilai suhu temperatur sekitar sebesar $35,30^{\circ} \mathrm{C}$

5. Kondisi alat yang mau Dalam keadaan ini diuji coba telah yang terjadi pada berpindah tempat di miniatur ruangan saat area halaman rumah di sebelum diuji dalam keadaan malam terdapat nilai suhu dan terlebih dahulu membaca suhu sekitar sebelum melakukan uji coba kembali.

6. Pengujian pertama Dalam keadaan ini dalam kondisi ini yang terjadi pada maka di uji kembali miniatur ruangan menggunakan media setelah diuji coba panas dari lilin terdapat nilai suhu sebanyak empat lilin temperatur sekitar dalam waktu 10 menit. sebesar $30,30^{\circ} \mathrm{C}$

7. Dalam pengujian Dalam keadaan ini kedua setelah lilin yang terjadi pada dimatikan dan di miniatur ruangan diamkan selama 10 setelah diuji coba menit.

terdapat nilai suhu temperatur sekitar sebesar $28,90^{\circ} \mathrm{C}$

8. Pengujian ketiga, Dalam keadaan ini dengan memasukkan yang terjadi pada media panas dari lilin miniatur ruangan sebanyak tiga lilin setelah diuji coba dalam waktu 10 menit terdapat nilai suhu temperatur sekitar sebesar $36,70^{\circ} \mathrm{C}$

9. Pengujian keempat, Dalam keadaan ini dengan memasukkan yang terjadi pada media panas dari lilin miniatur ruangan sebanyak satu lilin setelah diuji coba yang panjang dan terdapat nilai suhu hanya beberapa detik temperatur sekitar saja
TABEL III

PENGUJIAN SUHU BERHASIL DITURUNKAN DAN LAMA WAKTU PENURUNANNYA

\begin{tabular}{|c|c|c|c|c|c|c|}
\hline \multirow[t]{2}{*}{ No. } & $\begin{array}{l}\text { Nilai } \\
\text { suhu }\end{array}$ & $\begin{array}{c}\text { Wakt } \\
\mathrm{u}\end{array}$ & $\begin{array}{l}\text { Suhu yang } \\
\text { ditetapkan }\end{array}$ & \multicolumn{3}{|c|}{$\begin{array}{c}\text { Hasil Suhu yang } \\
\text { diturunkan }\end{array}$} \\
\hline & & & & 1 & 2 & 3 \\
\hline 1. & $42,70^{\circ} \mathrm{C}$ & $\begin{array}{c}3 \\
\text { detik }\end{array}$ & $\begin{array}{c}38,00^{0} \mathrm{C} \\
4 \text { fan berputar }\end{array}$ & $\begin{array}{l}41, \\
53 \\
{ }^{0} \mathrm{C}\end{array}$ & $\begin{array}{l}39, \\
90 \\
{ }^{0} \mathrm{C}\end{array}$ & $\begin{array}{c}37, \\
71^{0} \\
\text { C }\end{array}$ \\
\hline 2. & $37,71^{0} \mathrm{C}$ & $\begin{array}{c}2 \\
\text { detik }\end{array}$ & $\begin{array}{c}36,00^{\circ} \mathrm{C} \\
3 \text { fan berputar }\end{array}$ & $\begin{array}{l}36, \\
20 \\
{ }^{0} \mathrm{C}\end{array}$ & $\begin{array}{l}35, \\
35 \\
{ }^{0} \mathrm{C}\end{array}$ & \\
\hline 3. & $35,35^{0} \mathrm{C}$ & $\begin{array}{c}3 \\
\text { detik }\end{array}$ & $\begin{array}{c}33,00^{0} \mathrm{C} \\
2 \text { fan berputar }\end{array}$ & $\begin{array}{l}34, \\
80 \\
{ }^{0} \mathrm{C}\end{array}$ & $\begin{array}{l}33, \\
70 \\
{ }^{0} \mathrm{C}\end{array}$ & $\begin{array}{c}33, \\
00^{0} \\
\mathrm{C}\end{array}$ \\
\hline 4. & $33,00^{\circ} \mathrm{C}$ & $\begin{array}{c}1 \\
\text { detik }\end{array}$ & $\begin{array}{c}30,00^{\circ} \mathrm{C} \\
1 \text { fan berputar }\end{array}$ & $\begin{array}{l}30, \\
97 \\
{ }^{0} \mathrm{C}\end{array}$ & & \\
\hline 5. & $37,97^{0} \mathrm{C}$ & $\begin{array}{c}1 \\
\text { detik }\end{array}$ & $\begin{array}{c}29,00^{\circ} \mathrm{C} \\
\text { fan tidak ada } \\
\text { yang berputar }\end{array}$ & $\begin{array}{l}28, \\
50 \\
{ }^{0} \mathrm{C}\end{array}$ & & \\
\hline
\end{tabular}

Catatan: Dalam pengujian suhu ini terhadap lama waktu penurunannya tidak lah tetap untuk waktu dan suhunya yang turun, disebabkan situasi pengujian dan kondisi suhu saat pengujian dan pengujian ini juga sudah dicoba beberapa tempat dan hasilnya waktu penurunannya tidak sama.

Pengujian Aplikasi Voice Control pada Smartphone

Dalam pengujian Aplikasi Voice Control pada Smartphone berguna untuk menghubungkan bluetooth pada smartphone dengan bluetooth pada perangkat HC-05 yang telah dipasang pada alat pengendalian suhu ruangan, dimana aplikasi ini juga berfungsi sebagai awal perintah untuk di aktifkan agar kinerja pada alat pengendalian suhu ruangan langsung aktif dan menjalankan keseluruhan komponen. 
Page | 36

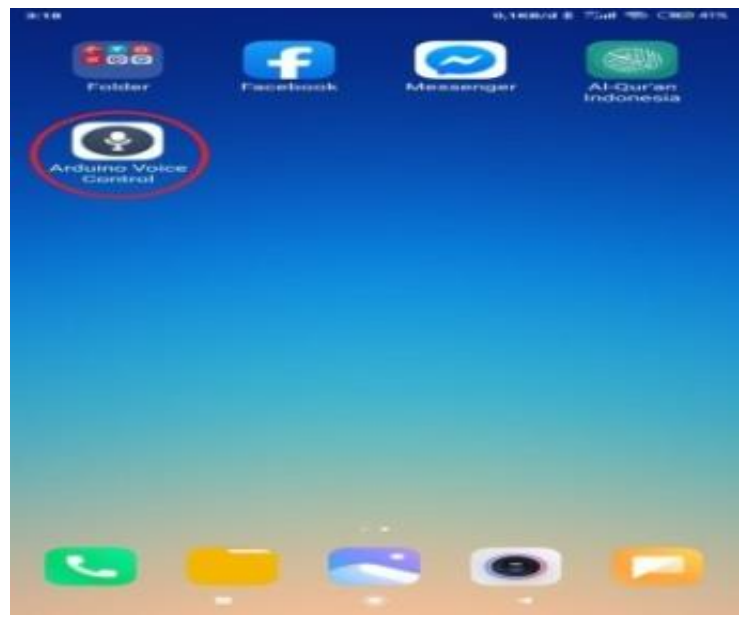

(a)

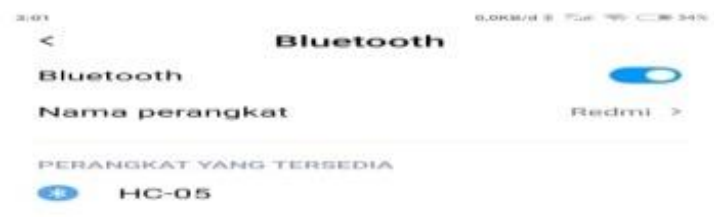

(b)

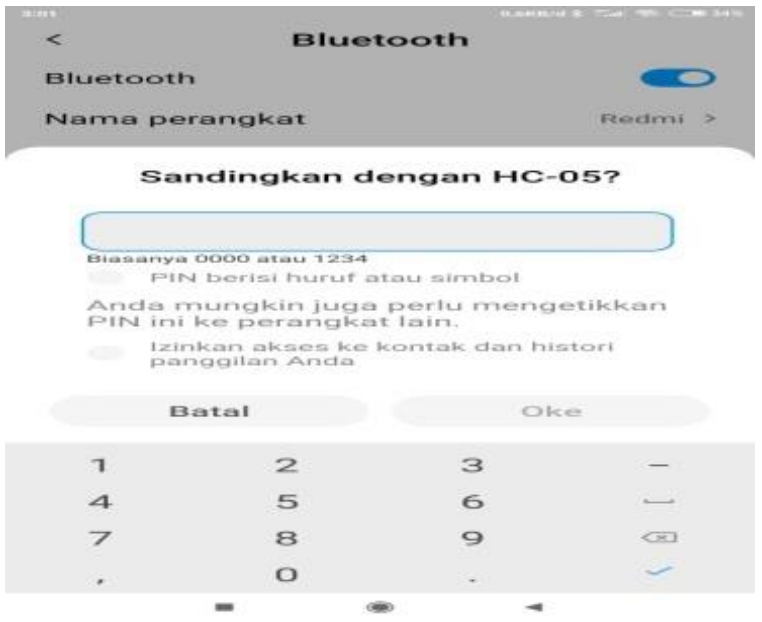

(c)

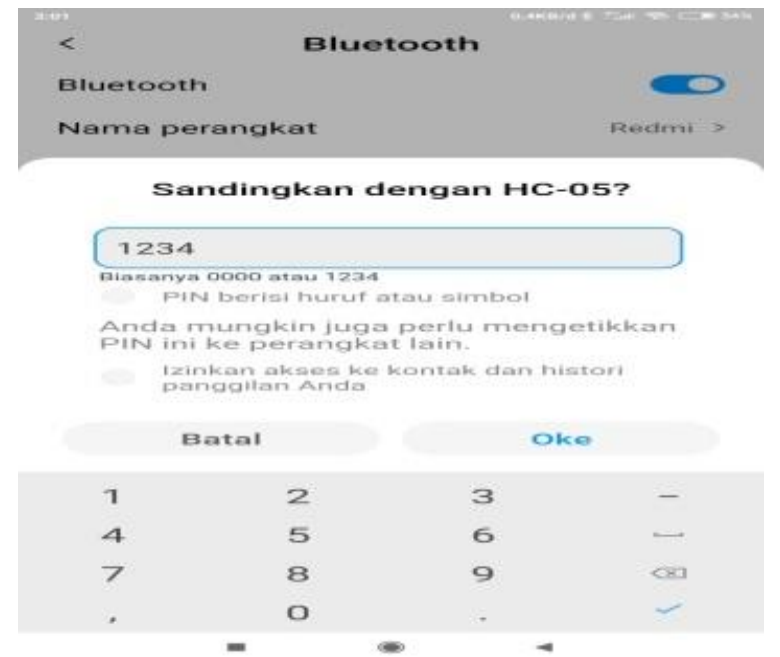

(d)

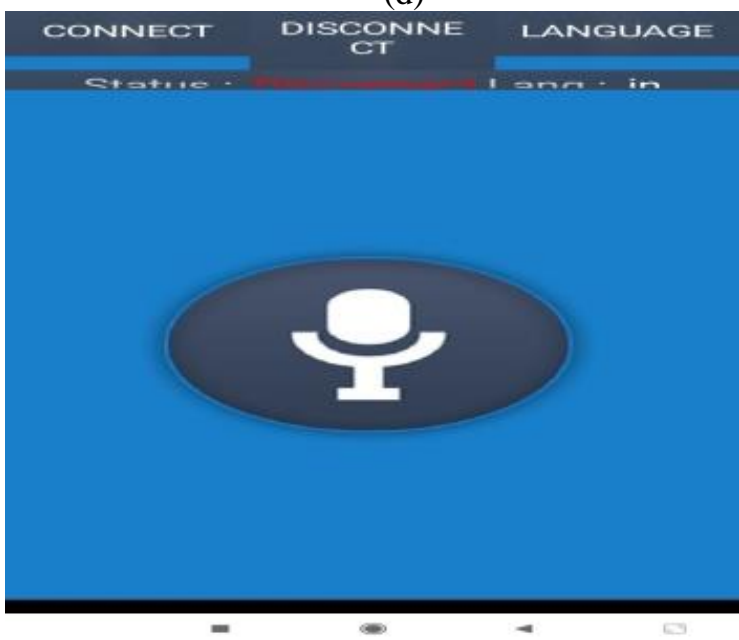

(e)

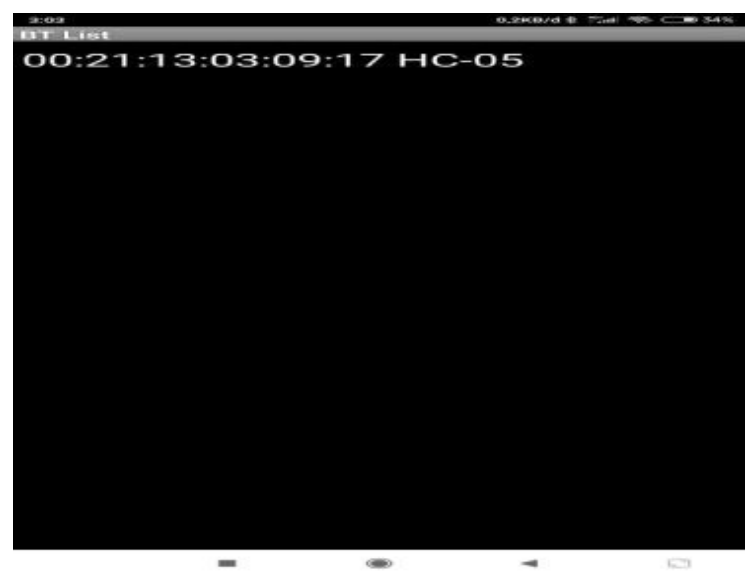

(f) 
Page | 37

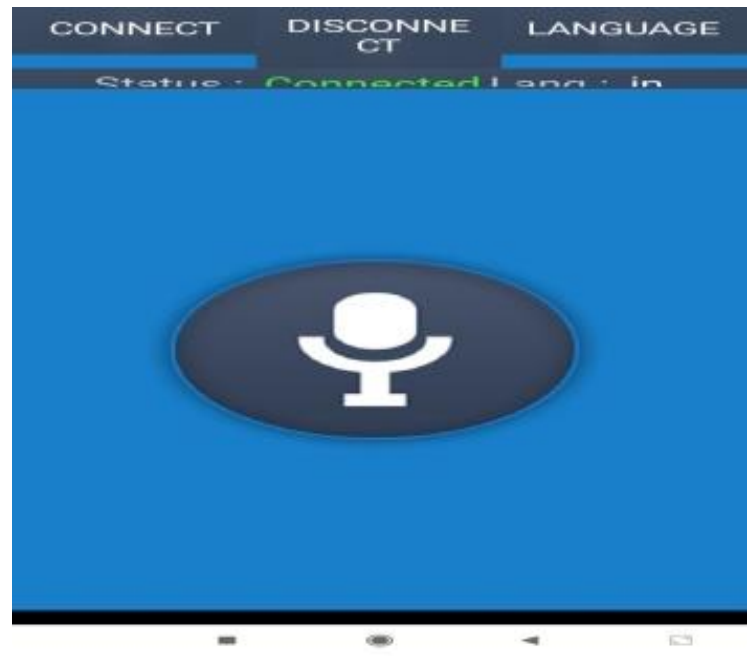

(g)

Gbr. 12 Keseluruhan langkah proses menghubungkan antara bluetooth pada smarthphone dengan bluetooth HC-05.

Penjelasan pada masing- masing pada gambar 12 antara lain sebagai berikut :

1. Pada gambar pertama (a), merupakan tampilan aplikasi di smartphone yang digunakan untuk menghubungkan ke dua bluetooth pada smartphone dengan HC-05.

2. Pada gambar kedua (b), merupakan tampilan bluetooth pada smartphone yang belum terhubung pada bluetooth $\mathrm{HC}-05$.

3. Pada gambar ketiga (c), merupakan tampilan saat memasuki bluetooth HC-05 dalam masih keadaan terkunci dan belum terhubung.

4. Pada gambar keempat (d), merupakan tampilan saat memasukkan kode kunci pada kolom kosong yang sudah tertera pada $\mathrm{HC}$ 05 dan lalu tekan ok maka koneksi kedua bluetooth saling terhubung tetapi belum bisa menjalan perintah terhadap alat pengendali suhu ruangan untuk berfungsi sebagaimana mestinya.

5. Pada gambar kelima (e), merupakan tampilan awal saat memasuki aplikasi voice control pada Smartphone dan keadaan ini masih dinyatakan belum terkoneksi antara kedua bluetooth.

6. Pada gambar keenam (f), merupakan tampilan saat telah mengklik connect dan pada tampilan ini tertera ip adress yang di HC-05 dan harus mengklik ip tersebut untuk menghubungkan ke dua bluetooth.

7. Pada gambar ketujuh (g), merupakan tampilan yang terhubung kedua bluetooth dengan perantara aplikasi ini dan untuk memulai perintah harus mengklik kembali pada gambar mikrofon yang berada ditengah kemudian nanti akan disuruh kembali untuk memasukkan suara dengan kode suaranya adalah "aktifkan" jika berhasil maka alat pada pengendalian suhu ruangan langsung bekerja dan jika kode suara yang dimasukkan tidak sama semestinya maka alat pengendalian suhu ruangan tidak berfungsi dan tidak menanggapinya dengan kode lain.

\section{KESIMPULAN DAN SARAN}

\section{A. Simpulan}

Berdasarkan hasil studi literatur, analisis, perancangan, implementasi, dan pengujian sistem ini, maka kesimpulan yang didapat adalah sebagai berikut

1. Perancangan dari alat pengendalian suhu ruangan menggunakan fan dan dht11 berbasis arduino telah berhasil dikerjakan sesuai dengan tujuan yang diharapkan.

2. Berdasarkan hasil percobaan kinerja sistem yang telah dilakukan, alat ini dapat bekerja cukup baik. Ternyata mendeteksi suhu tidak berpengaruh terhadap gelap atau terang pada ruangan disekitar pada saat uji coba tetapi suhu hanya bisa dibaca oleh udara panas nya yang disebabkan oleh cuaca.

\section{B. Saran}

Adapun saran-saran yang dapat diberikan penulis suntuk pengembangan dan perbaikan sistem ini selanjutnya adalah sebagai berikut:

1. Kepada peneliti selanjutnya diharapkan untuk lebih dapat mengoptimalkan keakuratan kecepatan putaran fan dc bila menggunakan fan dengan ukuran lebih besar.

2. Untuk peneliti selanjutnya bisa juga menambahkan beberapa sensor atau komponen terkait untuk mendapatkan hasil dari sistem pengendalian suhu ruangan agar kinerja lebih mudah dan fleksibel.

Kepada peneliti selanjutnya diharapkan dapat mengembangkan sistem pengendalian ruangan ini menjadi lebih baik lagi pada segala aspek agar terciptanya kenyamanan bagi orang yang berada didalamnya. 


\section{REFERENSI}

[1] H. Izzatul Islam et al., "Sistem Kendali Suhu Dan Page | 38 Pemantauan Kelembaban Udara Ruangan Berbasis Arduino Uno Dengan Menggunakan Sensor DHT22 Dan Passive Infrared (PIR)," 2016.

[2] S. J. Sokop, "Trainer Periferal Antarmuka Berbasis Mikrokontroler Arduino Uno," Train. Periferal Antarmuka Berbas. Mikrokontroler Arduino Uno, vol. vol.5 no.3, 2016.

[3] P. Ilmiah et al., "Pengendali kipas angin dari jarak jauh dengan arduino dan wifi," 2017.

[4] P. Giashinta, "Alat Pengatur Suhu Kelembaban dan Monitoring Masa Panen pada Budidaya Jamur Tiram Berbasis Arduino Uno," 2018.

[5] A. J. Lubis, R. Aulia, and H. Haris, "Monitoring Suhu udara Kawasan Gunung Aktif berbasis IoT," J. Teknol. dan Ilmu Komput. Prima, 2018.

[6] M. Saleh and M. Haryanti, "Rancang Bangun Sistem Keamanan Rumah Mengunakan Relay," J. Teknol. Elektro, 2017.

[7] M. A. Prasetya and R. Aulia, "Prototype Penerangan Lampu Taman Otomatis Menggunakan Arduino Uno," CESS (Journal Comput. Eng. Syst. Sci., 2020.

[8] H. Effendy and A. Y. A. P. , Riyadi Jimmy Iskandar, "Rancang Bangun Alat Pemberi Pakan Dan Pengganti Air Aquarium Otomatis Berbasis Arduino Uno," Ed. J. 2019. Vol7, No1, vol. Vol 7, No1, 2019.

[9] A. Faroqi, D. K. Halim, M. Sanjaya, and D. W. S. Ph, "Perancangan Alat Pendeteksi Kadar Polusi Udara Menggunakan Sensor Gas MQ-7 Dengan Teknologi Wireless HC-05," Ed. Juni 2017 Vol. X No. 2, 2017. 